OPEN ACCESS

Edited by:

Jochen C. Meier,

Technische Universitat

Braunschweig, Germany

Reviewed by:

Eric Hosy,

UMR5297 Institut Interdisciplinaire de

Neurosciences (IINS), France

Nicola Maggio,

Sheba Medical Center, Israel

${ }^{*}$ Correspondence:

Joachim Behr

joachim.behr@charite.de

tPresent address: Julia C. Bartsch,

Institute of Physiology I, Westfälische Wilhelms-Universität Münster, Münster, Germany

Received: 16 January 2020 Accepted: 17 March 2020

Published: 03 April 2020

Citation:

Bartsch JC and Behr J (2020) Noncanonical, Dopamine-Dependent Long-Term Potentiation at Hippocampal Output Synapses in a Rodent Model of First-Episode Psychosis.

Front. Mol. Neurosci. 13:55. doi: 10.3389/fnmol.2020.00055

\section{Noncanonical, Dopamine-Dependent Long-Term Potentiation at Hippocampal Output Synapses in a Rodent Model of First-Episode Psychosis}

\author{
Julia C. Bartsch ${ }^{1 \dagger}$ and Joachim Behr ${ }^{1,2 *}$ \\ ${ }^{1}$ Department of Psychiatry and Psychotherapy, Charité-Universitätsmedizin Berlin, Berlin, Germany, ${ }^{2}$ Department \\ of Psychiatry, Psychotherapy and Psychosomatic Medicine, Brandenburg Medical School, Neuruppin, Germany
}

Cognitive deficits and positive symptoms in schizophrenia have both been linked to hippocampal dysfunction. Recently, subregion-specific aberrant and maladaptive hippocampal synaptic plasticity has been suggested as one of the mechanistic underpinnings. The subiculum is the final output hub of the hippocampus and orchestrates hippocampal information transfer to other brain regions. While most CA1 pyramidal neurons show regular-spiking behavior, subicular output neurons comprise bursting and regular-firing pyramidal cells. These two cell types target different brain regions and express unique forms of synaptic plasticity. Here, we used a single systemic application of the noncompetitive glutamatergic $\mathrm{N}$-methyl-D-aspartate receptor (NMDAR) antagonist MK-801 to model first-episode psychosis in rats and studied long-term potentiation (LTP) in subicular regular-firing cells in acute hippocampal slices. Previously, we have reported a facilitation of a presynaptic, late-onset LTP in subicular bursting pyramidal cells after systemic NMDAR antagonism. Here, we show that single systemic NMDAR antagonist application also facilitates the induction of a noncanonical, but postsynaptic NMDAR-independent LTP in ventral subicular but not in CA1 regular-firing pyramidal cells. This form of LTP was dependent on D1/D5 dopamine receptor activation. Activation of D1/D5 dopamine receptors by a specific agonist mimicked and occluded LTP induced by electrical high-frequency stimulation (HFS). Furthermore, our results indicate that this form of LTP relies on postsynaptic $\mathrm{Ca}^{2+}$ signaling and requires the activation of protein kinase $\mathrm{A}$. Considering the pivotal role of the subiculum as information gatekeeper between the hippocampus and other brain regions, this aberrant LTP in ventral subicular regular-firing neurons is expected to interfere with physiological hippocampal output processing and might thereby contribute to hippocampal dysfunction in psychotic events.

Keywords: hippocampus, schizophrenia, synaptic plasticity, subiculum, psychosis, long-term potentiation, MK-801, dopamine 


\section{INTRODUCTION}

Roughly one percent of the global population is affected by schizophrenia. This multifaceted, heterogeneous psychiatric disorder is characterized by positive symptoms, i.e., delusions or hallucinations, negative symptoms, e.g., anhedonia, and cognitive symptoms including aberrant hippocampus-dependent memory encoding and retrieval as well as novelty detection (Heckers et al., 1998; Zierhut et al., 2010; Tamminga et al., 2012b; Pirnia et al., 2015; Ragland et al., 2015; Schott et al., 2015). In light of the accumulating evidence from large-scale genetic studies (Hall et al., 2015), contemporary pathophysiological concepts of schizophrenia suggest aberrations of synaptic plasticity are core to schizophrenia (McGlashan, 2006; Averbeck and Chafee, 2016). Synaptic plasticity in neuronal networks is regarded as one of the underpinning mechanisms for learning and memory enabling the individual to cope with a changing environment. Long-term potentiation (LTP) is one form of synaptic plasticity, defined by a lasting increase in synaptic efficacy following prior activity (Bliss and Lomo, 1973). Hippocampal dysfunction has been linked to both cognitive deficits and positive symptoms in schizophrenia (Bogerts, 1997) and hippocampal dysfunction in rodent model psychosis comprises subregion-specific maladaptive synaptic plasticity (Tamminga et al., 2012a). While no single animal model can completely match all aspects of an inherently human psychiatric disorder like schizophrenia, animal models are key to investigate the neurobiological mechanisms of schizophrenia at the cellular level (Averbeck and Chafee, 2016). Certain cognitive facets of schizophrenia can satisfactorily be modeled and studied in rodents by administering antagonists of the glutamatergic N-methyl-D-aspartate receptor (NMDAR, Neill et al., 2010). This rodent psychosis model originates from the NMDAR hypofunction concept which builds on the observation that acutely given NMDAR antagonists can induce psychosis in healthy humans similar to positive, negative and cognitive symptoms of schizophrenia (Luby et al., 1959). The hippocampal formation consists of the cornu ammonis (CA1-CA3 in rodents, hippocampus proper), the dentate gyrus and the subiculum. The dorsal hippocampus is mainly associated with spatial learning, while the ventral hippocampus is involved in emotion- and motivation-related processes (Fanselow, 2000; Bannerman et al., 2004; reviewed in Jarrard, 1995; Moser and Moser, 1998; Maren, 1999; Sharp, 1999; Fanselow and Dong, 2010; Segal et al., 2010; reviewed in Strange et al., 2014). The subiculum is the final output hub of the hippocampus and orchestrates hippocampal information transfer to other brain regions (O'Mara et al., 2000; Aggleton and Christiansen, 2015). Subicular pyramidal neurons can be distinguished in regular-spiking and burstspiking neurons (Stewart and Wong, 1993; Taube, 1993; Behr et al., 1996; Mattia et al., 1997; Staff et al., 2000; Harris and Stewart, 2001; Wellmer et al., 2002), both show cell type-specific LTP (Wozny et al., 2008a,b) and target different brain regions. Previously, we have reported a facilitation of a presynaptic, late-onset LTP in subicular bursting pyramidal cells after systemic NMDAR antagonism (Bartsch et al., 2015). Here, we used a single systemic application of the noncompetitive
NMDAR antagonist MK-801 to model psychosis in rats and studied LTP specifically in ventral subicular regular-firing cells in acute hippocampal slices.

\section{MATERIALS AND METHODS}

\section{Animals}

All experiments were carried out under the directive 2010/63/EU of the European Parliament and of the council of 22 September 2010. Ethical approval for all rats used in this study was obtained from the Landesamt für Gesundheit und Soziales Berlin (LAGeSo Berlin, Germany). Rats were kept on a 12 h light-dark cycle and had access to food and water ad libitum. Wistar rats of both sexes (4-6 weeks old) received a single intraperitoneal injection with either MK-801 [(5S,10R)-(+)-5-methyl-10,11-dihydro-5Hdibenzo(a,d)cyclohepten-5,10-imine maleate, $5 \mathrm{mg} / \mathrm{kg}$ body weight], or $0.9 \%$ saline ( $10 \mathrm{ml} / \mathrm{kg}$ body weight).

\section{Slice Preparation}

Twenty-four hours after i.p. injection, rats were decapitated under deep anesthesia (isoflurane, 1-chloro-2,2,2-trifluoroethyldifluoromethylether; $2.5 \%$ in $\mathrm{O}_{2}$ ) and the brains were quickly removed. Horizontal slices $(350-400 \mu \mathrm{m})$ containing the hippocampal formation and the entorhinal cortex were obtained with a Leica VT1200S vibratome (Leica Microsystems CMS, Mannheim, Germany). Slices were collected from the ventral sector of the hippocampus ( $\sim 2 \mathrm{~mm}$ of the temporal pole), avoiding the extreme $350 \mu \mathrm{m}$ end (Maggio and Segal, 2007a). Tissue for sharp microelectrode recordings was prepared in ice-cold, oxygenated $\left(95 \% \mathrm{O}_{2}, 5 \% \mathrm{CO}_{2}\right)$ artificial cerebrospinal fluid (ACSF) and the slices were transferred for storage to an interface recording chamber continuously perfused $(1.5-2 \mathrm{ml} / \mathrm{min})$ with oxygenated and prewarmed $\left(34^{\circ} \mathrm{C}\right) \mathrm{ACSF}$. The composition of the ACSF was as follows (in $\mathrm{mM}$ ): $\mathrm{NaCl} 129, \mathrm{Na}_{2} \mathrm{PO}_{4}$ 1.25, $\mathrm{NaHCO}_{3}$ 26, $\mathrm{KCl} 3, \mathrm{CaCl}_{2}$ 1.6, $\mathrm{MgSO}_{4}$ 1.8, glucose 10 at a $\mathrm{pH}$ of 7.4. Slices for patchclamp recordings were prepared in ice-cold, saccharose-based ACSF (in mM): $\mathrm{NaCl} 87, \mathrm{Na}_{2} \mathrm{PO}_{4} 1.25, \mathrm{NaHCO}_{3} 26, \mathrm{KCl}$ 2.5, $\mathrm{CaCl}_{2}$ 0.5, $\mathrm{MgCl}_{2} 7$, saccharose 75 , glucose 25 at a $\mathrm{pH}$ of 7.4. After preparation, slices were kept under submerged conditions at $35^{\circ} \mathrm{C}$ for approximately $30 \mathrm{~min}$ and were then transferred to physiological ACSF solution at room temperature for further storage.

\section{Electrophysiology}

Single-cell recordings in ventral CA1 pyramidal cells and regular-firing pyramidal cells of the subiculum were performed with sharp microelectrodes (40-100 $\mathrm{M} \Omega$ ) filled with $2.5 \mathrm{M}$ potassium acetate in current-clamp bridge mode at resting membrane potential. Patch-clamp recordings were performed under submerged conditions at room temperature in voltageclamp mode at a holding potential of $-70 \mathrm{mV}$. Patch-clamp electrodes (4-6 M $\Omega$ ) were filled with (in $\mathrm{mM}$ ): K-gluconate 135, $\mathrm{KCl}$ 20, HEPES 10, phosphocreatine 7, Mg-ATP 2, Na-GTP 0.3 , EGTA 0.2 and adjusted with $\mathrm{KOH}$ to a $\mathrm{pH}$ of 7.2. Access resistance was monitored throughout the experiments and recordings with fluctuating access resistance were discarded. No 
series resistance compensation was used. Signals were low-pass filtered at $3 \mathrm{kHz}$, sampled at $10 \mathrm{kHz}$ by an ITC-16 interface (Instrutech Corp., Great Neck, NY, USA) and processed by TIDA software (HEKA GmbH, Lambrecht, Germany).

To study synaptic plasticity at glutamatergic synapses, all experiments were performed in the presence of bicuculline $(5 \mu \mathrm{M})$ to block $\mathrm{GABA}_{\mathrm{A}}$ receptor-mediated responses. To prevent polysynaptic responses, concentrations of $\mathrm{MgSO}_{4}$ and $\mathrm{CaCl}_{2}$ were elevated to $4 \mathrm{mM}$ each (Nicholls and Purves, 1970; Berry and Pentreath, 1976; Wigström and Gustafsson, 1983; Miles and Wong, 1987; Wozny et al., 2008a). Excitatory postsynaptic potentials or currents (EPSP/EPSC) were evoked at $0.1 \mathrm{~Hz}$ by stimulation $(100 \mu \mathrm{s})$ of Schaffer collaterals or CA1 efferents with an ACSF-filled patch pipette or a bipolar stimulating electrode. Baseline responses were recorded for at least $10 \mathrm{~min}$ and the stimulus intensity was set to evoke amplitudes of $30-50 \%$ of the maximum response. Depending on the rationale of the experiment, different high-frequency stimulation (HFS) protocols were used for the induction of LTP. Two-hundred pulses at $50 \mathrm{~Hz}, 25$ pulses at $50 \mathrm{~Hz}$, or 10 pulses at $40 \mathrm{~Hz}$. Changes in synaptic strength were measured for $30 \mathrm{~min}$ after induction. Amplitudes of evoked EPSP or EPSC were normalized to baseline values. LTP was calculated by averaging the responses collected during the last $5 \mathrm{~min}$ of each experiment. Paired-pulse index (PPI) was investigated by analyzing the ratio of the second to the first synaptic response (EPSP2/EPSP1) at an inter-stimulus interval of 60 ms (Zucker and Regehr, 2002).

\section{Data Analysis/Statistics}

Electrophysiological data were analyzed offline with Clampfit software (Molecular Devices Corporation, Sunnyvale, CA, USA), TIDA software (HEKA GmbH, Lambrecht, Germany) and GraphPad Prism (GraphPad Software, La Jolla, CA, USA). All datasets were tested for significant outliers using the Grubbs' test (significance level, $p<0.05$ ). Data are presented as mean \pm standard error of the mean (SEM) or box and whisker plots (box: 25th to 75th percentiles, whiskers 5th and 95th percentiles). In figures illustrating the experimental time course of normalized amplitudes, data points were binned from six consecutive responses. Representative traces are shown as averages of six responses with clipped stimulation artifacts. The significance level was set to $p<0.05$. Comparisons within groups were analyzed by paired Student's $t$-tests. Multigroup comparisons were analyzed with the Kruskal-Wallis test followed by Dunn's post hoc test against the control group (Figures 2F, 3E). Numbers given in the text $(x / y)$ refer to numbers of neurons $(\mathrm{x})$ recorded in different animals $(\mathrm{y})$.

\section{Drugs}

The following drugs were used: (+)-MK-801 maleate [(5S,10R)(+)-5-methyl-10,11-dihydro-5H-dibenzo(a,d)cyclohepten-5,10imine maleate], (-)-bicuculline methiodide $\left(\left(\mathrm{R}-\left(\mathrm{R}^{\star}, \mathrm{S}^{*}\right)\right)-5-(6\right.$, 8-dihydro-8-oxofuro(3,4-e)-1,3-benzodioxol-6-yl)-5,6,7,8tetrahydro-6,6-dimethyl-1,3-dioxolo(4,5-g)isoquinolinium iodide), $5 \mu \mathrm{M}$; SCH23390 hydrochloride ((R)-(+)-7-chloro8-hydroxy-3-methyl-1-phenyl-2,3,4,5-tetrahydro-1H-3-

benzazepine hydrochloride), $10 \mu \mathrm{M}$; SKF38393 hydrobromide
(( \pm )-1-phenyl-2,3,4,5-tetrahydro-(1H)-3-benzazepine-7,8-diol hydrobromide), $100 \mu \mathrm{M}$; D-AP5 (D-(-)-2-amino-5phosphonopentanoic acid), $100 \mu \mathrm{M}$; (RS)-MCPG ((RS)- $\alpha$ methyl-4-carboxyphenylglycine), $500 \mu \mathrm{M}$; BAPTA (1,2-bis(2aminophenoxy)ethane- $\mathrm{N}, \mathrm{N}, \mathrm{N}^{\prime}, \mathrm{N}^{\prime}$-tetraacetic acid), $30 \mathrm{mM}$ in the intracellular solution; Rp-8-CPT-cAMPS (8-(4chlorophenylthio)adenosine- $3^{\prime}, 5^{\prime}$-cyclic monophosphorothi oate), $100 \mu \mathrm{M}$. Drugs were purchased from Biolog, Germany; Sigma-Aldrich, Germany; Ascent Scientific, UK and Tocris, UK. Most drugs were bath-applied for at least $10 \mathrm{~min}$ before starting the experiment. In experiments using the PKA inhibitor Rp-8-CPT-cAMPS, slices were incubated for at least $1 \mathrm{~h}$ before commencement of recordings. Loading recorded neurons with the calcium chelator BAPTA did not alter the discharge behavior of subicular pyramidal cells. Stable baseline responses could be obtained in most of the recordings with BAPTA. Cells that showed a rundown of responses $(\sim 15 \%$, Lapointe et al., 2004) were not included.

\section{RESULTS}

\section{Facilitated LTP in Ventral Subicular but Not in CA1 Pyramidal Neurons Following Systemic NMDAR Antagonism}

As systemic NMDAR antagonism has been reported to facilitate a noncanonical late-onset LTP at CA1-subiculum synapses to bursting pyramidal cells (Bartsch et al., 2015), we first studied whether this holds also true for ventral CA1-subiculum synapses to regular-firing pyramidal cells. Recordings were performed in regular-firing pyramidal cells in the middle portion of the subiculum concerning the proximodistal axis using sharp microelectrodes to leave the intracellular environment physiological (Figures 1A,B). We applied a brief HFS protocol (10 pulses, $40 \mathrm{~Hz}$ ), which was insufficient to induce LTP at CA1-subiculum synapses to regular-firing pyramidal cells under control conditions $(0.99 \pm 0.08, n=7 / 6, p=0.78$; Figures $1 \mathrm{C}-\mathrm{E})$. In MK-801-treated rats, however, the subthreshold HFS induced stable LTP appearing as a lasting late-onset increase in EPSP amplitudes in subicular regular-firing pyramidal cells $(2.12 \pm 0.28, n=7 / 5, p<0.01$; Figures 1C-E). Previously, we have shown that this brief HFS does not induce LTP at CA3-CA1 synapses in MK-801-treated rats (Bartsch et al., 2015). Here, we also tested an adapted, slightly stronger brief HFS protocol (25 pulses, $50 \mathrm{~Hz}$ ) set subthreshold for LTP induction in control rats in CA1 pyramidal cells. In line with our previous results, this adapted brief HFS also failed to induce LTP (control: $0.98 \pm 0.11$, $n=6 / 5, p=0.78$; MK-801: $1.20 \pm 0.10, n=5 / 4, p=0.15$; Figures $\mathbf{1 F}-\mathbf{H})$. Hence, we conclude that this form of LTP is exclusive to subicular regular-firing pyramidal neurons.

\section{Facilitated LTP in Regular-Firing Subicular Neurons of MK-801-Treated Rats Is Expressed Postsynaptically and Is Dependent on Postsynaptic $\mathrm{Ca}^{2+}$}

To investigate the expression site of this facilitated LTP in regular-firing subicular neurons of $\mathrm{MK}-801$-treated rats, we 


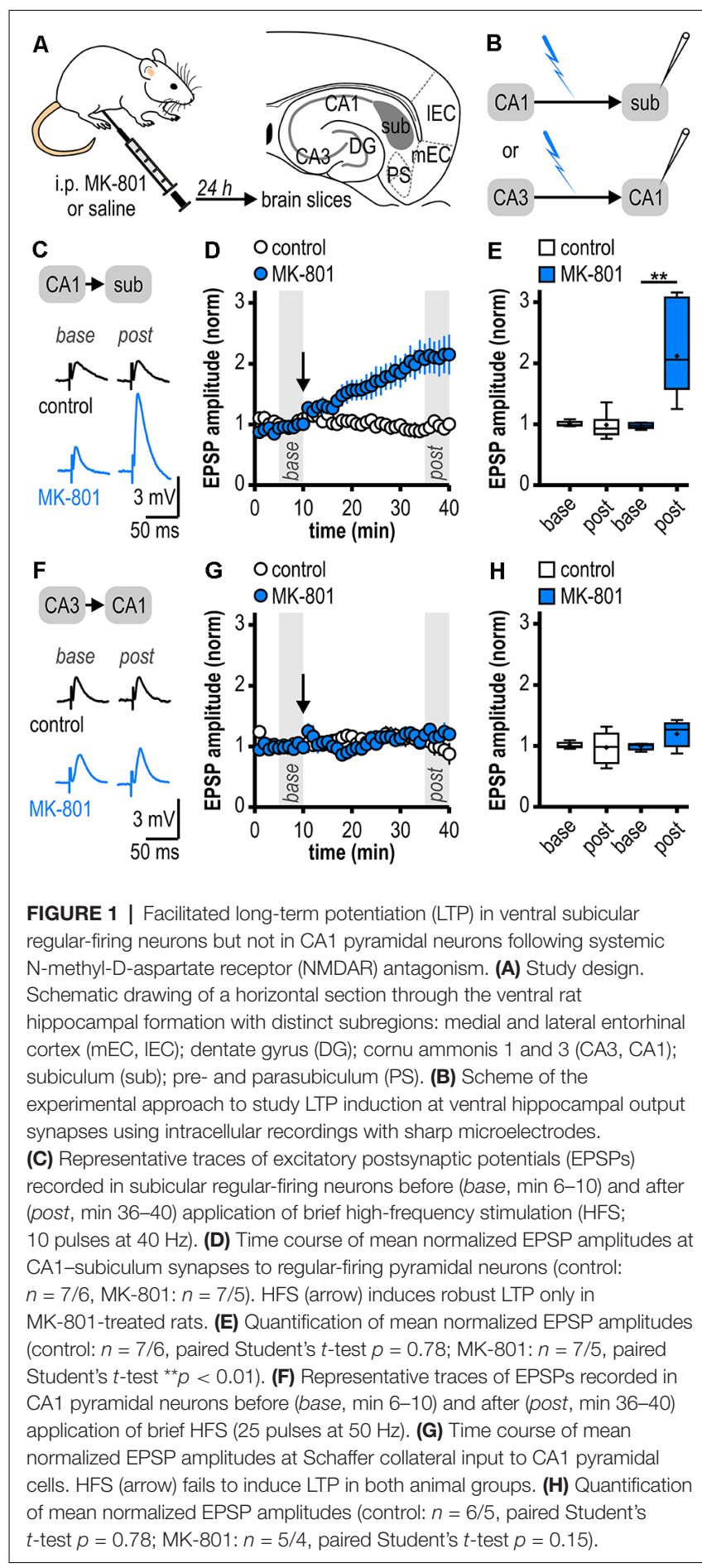

analyzed the PPI before and after LTP induction (Zucker and Regehr, 2002). The facilitated LTP in regular-firing neurons of MK-801-treated rats was not associated with significant changes in the PPI (base: $1.30 \pm 0.18$, LTP: $1.28 \pm 0.12, n=7 / 5$, $p=0.79$; Figures $2 \mathrm{~A}-\mathrm{C}$ ), arguing for a postsynaptic expression site. In the next step, we determined if postsynaptic $\mathrm{Ca}^{2+}$ signaling is required for this facilitated LTP in regular-firing neurons of MK-801-treated rats. To this end, we performed

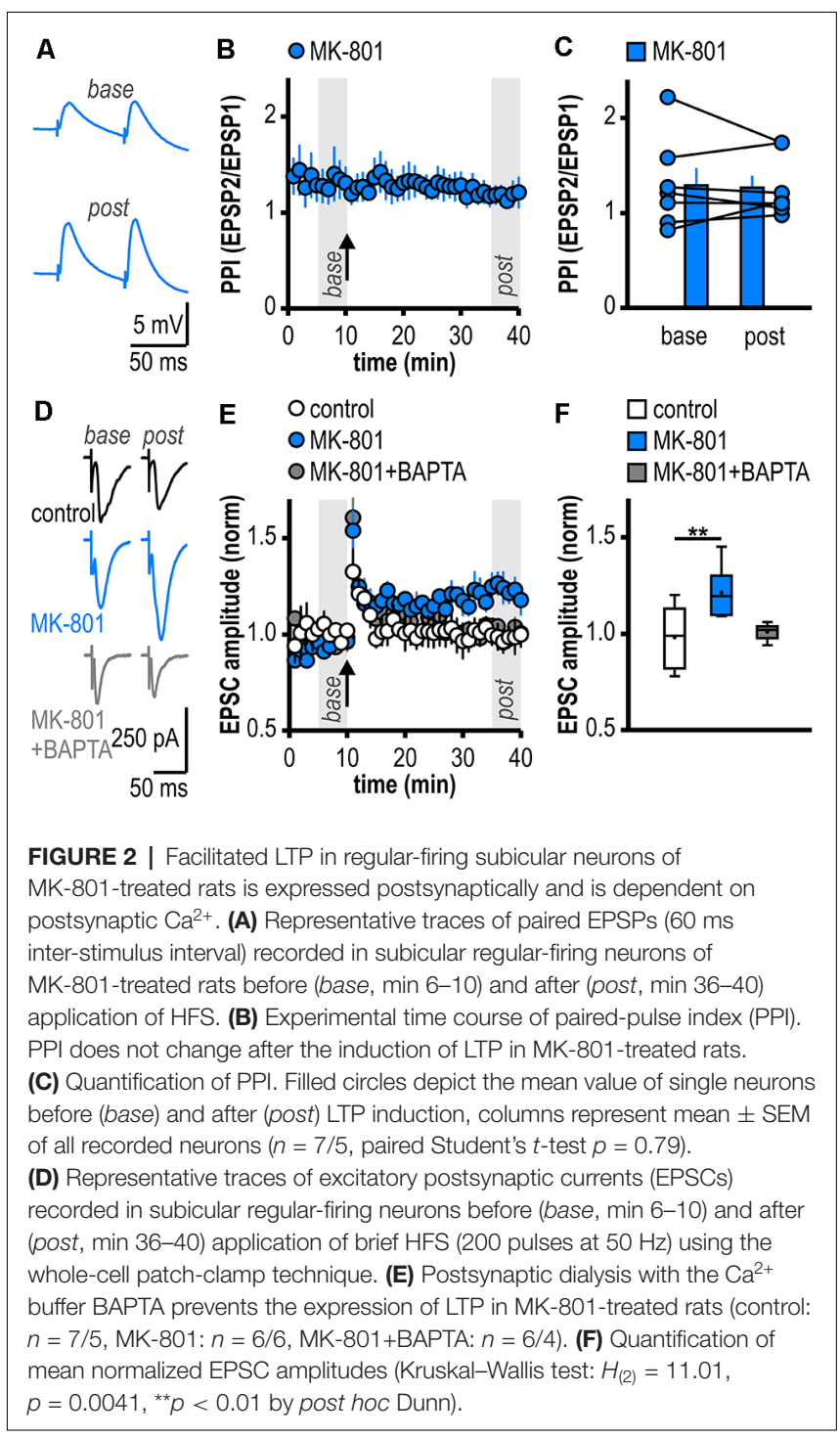

whole-cell patch-clamp recordings to guarantee good dialysis of cells with a $\mathrm{Ca}^{2+}$ buffer. To replicate the LTP in MK-801treated animals under patch-clamp conditions, we adjusted the HFS to 200 pulses at $50 \mathrm{~Hz}$ applied in current-clamp mode. This stimulation protocol induced LTP in MK-801-treated rats $(1.21 \pm 0.05, n=6 / 6, p<0.01$; Figures $2 \mathrm{D}-\mathrm{F})$, but led to only brief post-tetanic potentiation and no LTP in control animals $(1.01 \pm 0.02, n=7 / 5, p=0.68$; Figures 2D-F). As previously reported (Wozny et al., 2008b; Bartsch et al., 2015), in whole-cell patch-clamp recordings under submerged conditions LTP was smaller than in sharp microelectrode recordings under interface condition. Of note, LTP in patch-clamp recordings under submerged conditions exhibited a different time course lacking the late-onset component. A reasonable explanation for this observation might be a difference in oxygen supply under both recording conditions (Hájos et al., 2009). Postsynaptic dialysis of individual regular-firing neurons with the fast $\mathrm{Ca}^{2+}$ buffer BAPTA prevented the induction of LTP in MK-801treated rats $(1.01 \pm 0.02, n=6 / 4, p=0.56$; Figures $2 \mathrm{D}-\mathrm{F})$, 
suggesting that this facilitated LTP in subicular regular-firing neurons after systemic NMDAR antagonism is dependent on postsynaptic $\mathrm{Ca}^{2+}$ signaling.

\section{Noncanonical LTP in MK-801-Treated Rats Depends on the Activation of D1/D5R and the Adenylate Cyclase-cAMP-PKA Signaling Cascade but Is Independent of NMDAR and mGluRI/II}

At various synapses in the central nervous system, LTP depends on NMDAR activation (Nicoll and Malenka, 1999; Morris, 2013; Volianskis et al., 2015). Also, subicular regular-firing neurons express NMDAR-dependent LTP (Wozny et al., 2008b). However, the application of the NMDAR antagonist AP5 failed to prevent the aberrant LTP in MK-801-treated rats (2.70 \pm 0.49 , $n=6 / 5$; Figures $3 \mathrm{~A}, \mathrm{E}$ ). This suggests that this late-onset LTP after systemic MK-801 treatment is NMDAR-independent. To test the involvement of metabotropic glutamate receptors (mGluR) in this NMDAR-independent LTP (O'Leary and O'Connor, 1999), we bath-applied the mGluRI/II antagonist MCGP. Again, this could not prevent LTP induction in regular-firing neurons from MK-801-treated rats ( $2.32 \pm 0.40, n=5 / 5$; Figures $3 B, E)$. This argues against a major involvement of $\mathrm{mGluR}$ in this aberrant form of LTP.

Previously, we have reported a facilitation of a presynaptic, late-onset LTP in subicular bursting pyramidal cells after systemic NMDAR antagonism that is induced by D1/D5 dopamine receptor (D1/D5R) activation (Bartsch et al., 2015). Thus, we tested if the facilitated LTP in subicular regular-firing neurons is also mediated by D1/D5R. Indeed, in the presence of the specific D1/D5R antagonist SCH23390, LTP-induction was blocked (1.06 $\pm 0.15, n=6 / 4$; Figures 3C,E). $\mathrm{D} 1 / \mathrm{D} 5 \mathrm{R}$ are $\mathrm{G}$ protein-coupled receptors that stimulate the adenylate cyclase-cAMP-protein kinase A (PKA) signaling cascade (Missale et al., 1998). Consequently, we investigated whether blocking this pathway prevents the induction of LTP in MK-801-treated animals. To this end, hippocampal brain slices were incubated with the PKA inhibitor Rp-8-CPT-cAMPS for at least $1 \mathrm{~h}$ before recording. Indeed, this treatment blocked the induction of LTP in MK-801-treated animals (1.10 \pm 0.11 , $n=5 / 3$; Figures 3D,E), indicating that this form of LTP needs the activation of PKA. A summary of changes in synaptic strength in the reported experiments is shown in Figure 3E.

\section{D1/D5R Activation Mimics and Occludes Noncanonical HFS-Induced LTP in MK-801-Treated Rats}

If D1/D5R activation is crucial for the aberrant LTP in MK801-treated rats, activating these receptors by a specific agonist should also result in LTP. Accordingly, bath application of the specific D1/D5R agonist SKF38393 resulted in an enhancement of synaptic transmission in subicular regular-firing neurons of MK-801 treated rats $(1.76 \pm 0.12, n=5 / 4, p<0.01$; Figures 4A-C) which mimicked and finally occluded tetanusinduced LTP $(1.10 \pm 0.06, n=5 / 4, p=0.52$; Figures $4 \mathrm{D}-\mathrm{F})$.
This shows that chemically and electrically induced LTP share common mechanisms.

\section{DISCUSSION}

The present findings confirm and extend previous studies on aberrant hippocampal LTP in a rodent model of acute psychosis. We show that single systemic NMDAR antagonism in young adult Wistar rats facilitates LTP induction at ventral CA1-subiculum synapses to regular-firing pyramidal cells tested ex vivo 1 day later. This noncanonical, late-onset LTP in MK-801treated rats is postsynaptic, NMDAR-independent and relies on the activation of D1/D5R, PKA, and postsynaptic $\mathrm{Ca}^{2+}$ signaling.

\section{Subregion-Specific Changes in Hippocampal LTP in the MK-801 Rodent Model of First-Episode Psychosis}

Previous ex vivo studies using acute brain slices have shown that a single systemic application of MK-801 can impair LTP at the Schaffer collateral input to CA1 (Wöhrl et al., 2007; Bartsch et al., 2015). Likewise, LTP at the direct cortical input to CA1 was reduced for prolonged periods (Wöhrl et al., 2007). Accordingly, we here also found no facilitation of LTP at the Schaffer collateral input to CA1. The facilitated LTP was exclusive to regular-firing subicular neurons. In line with our results, ex vivo field potential recordings at CA1-subiculum synapses indicated facilitated LTP $24 \mathrm{~h}$ after a single systemic application of MK-801 (Buck et al., 2006). Therefore, our and previous results argue for subregion-specific patterns of psychosis-induced changes in hippocampal LTP. Notably, the facilitation of LTP seems to be restricted to subicular hippocampal output synapses. The distinct propensity of subicular pyramidal cells to successfully express LTP might depend on various presynaptic and postsynaptic factors as the total number of synaptic contacts, presynaptic and postsynaptic $\mathrm{Ca}^{2+}$ influx, the number of release-competent vesicles or the desensitization state of postsynaptic receptors (Schneggenburger et al., 2002) and has to be delineated in more detail in future studies.

\section{Cell Type-Specific Aberrant LTP at Hippocampal Output Synapses in the MK-801 Rodent Model of First-Episode Psychosis}

Adding up to the complexity, while most CA1 pyramidal neurons show regular-spiking behavior, subicular output neurons comprise bursting and regular-firing pyramidal cells (Stewart and Wong, 1993; Taube, 1993; Behr et al., 1996; Mattia et al., 1997; Staff et al., 2000; Harris and Stewart, 2001; Wellmer et al., 2002). These two cell types target different brain regions. Bursting pyramidal cells project to the presubiculum, the medial entorhinal cortex, the hypothalamus, and the retrosplenial cortex while regular-firing pyramidal cells target the lateral entorhinal cortex, the nucleus accumbens and the amygdala (Köhler, 1985; Stewart, 1997; Kim and Spruston, 2012). Interestingly, CA1 efferents to subicular 

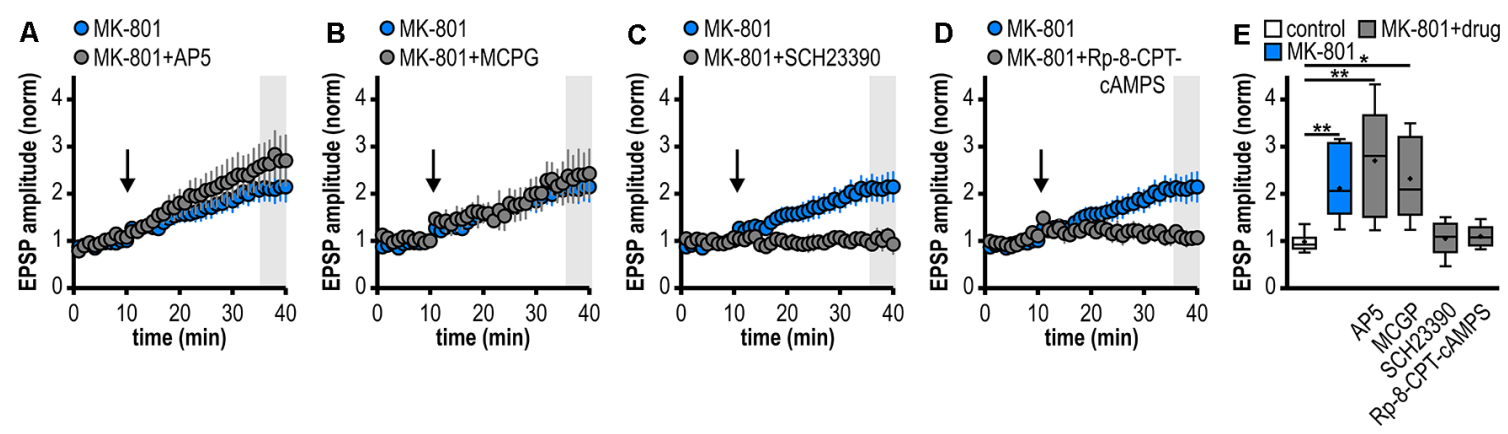

FIGURE 3 | Noncanonical LTP in MK-801-treated rats depends on the activation of D1/D5R and the adenylate cyclase-cAMP-PKA signaling cascade but is independent from NMDAR and mGluRI/II. (A-D) Time course of mean normalized EPSP amplitudes at CA1-subiculum synapses to regular-firing pyramidal neurons under the bath-application of denoted drugs. MK-801 data taken from Figure 1D is replotted for comparison. (A) The NMDAR antagonist AP5 failed to prevent LTP in MK-801-treated rats ( $n=6 / 5$, paired Student's $t$-test $p<0.05)$. (B) The mGluRI/II antagonist MCGP could not block LTP induction ( $n=5 / 5$, paired Student's $t$-test $p<0.05)$. (C) The specific D1/D5R antagonist SCH23390 blocked LTP-induction ( $n=6 / 4$, paired Student's $t$-test $p=0.64)$. (D) Preincubation of slices with the PKA inhibitor Rp-8-CPT-cAMPS prevented the induction of LTP ( $n=5 / 3$, paired Student's $t$-test $p=0.68)$. (E) Summary of changes in synaptic strength following brief HFS for the different experimental groups shown in (A-D). Control and MK-801 data taken from Figure 1E is replotted for comparison. Quantification of mean normalized EPSP amplitudes (Kruskal-Wallis test: $H_{(5)}=23.18, p=0.0003,{ }^{\star} p<0.05,{ }^{\star *} p<0.01$ by post hoc Dunn).

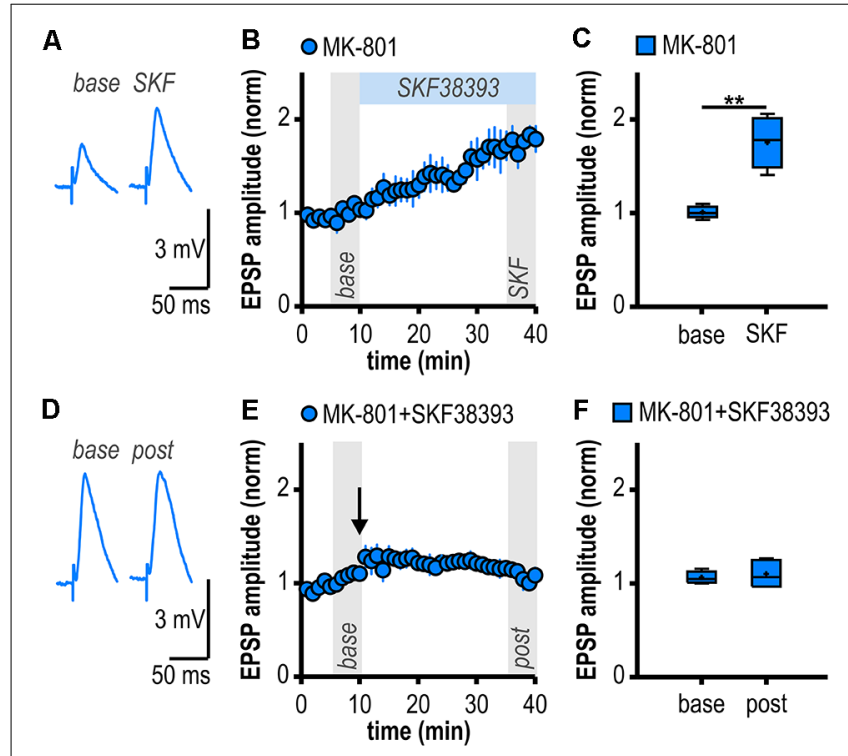

FIGURE 4 | D1/D5R activation mimics and occludes noncanonical HFS-induced LTP in MK-801-treated rats. (A) Representative traces of EPSPs recorded in subicular regular-firing neurons before (base, min 6-10) and after (SKF, min 36-40) application of the D1/D5R agonist SKF38393. (B) Time course of mean normalized EPSP amplitudes at CA1-subiculum synapses to regular-firing pyramidal neurons. D1/D5R activation enhanced EPSPs in subicular regular-firing pyramidal neurons in MK-801-treated rats. (C) Quantification of mean normalized EPSP amplitudes $(n=5 / 4$, paired Student's $t$-test, $\left.{ }^{* *} p<0.01\right)$. (D) Representative traces of EPSPs recorded in subicular regular-firing neurons before (base, min 6-10) and after (post, min 36-40) application of brief HFS following D1/D5R activation.

(E) SKF38393-induced enhancement of EPSPs prevented HFS-induced LTP (continued recordings of the same cells shown in B). (F) Quantification of mean normalized EPSP amplitudes (paired Student's $t$-test, $p=0.52$ ).

pyramidal cells innately express cell type-specific forms of synaptic plasticity (Fidzinski et al., 2008; Wozny et al., 2008a,b; Aoto et al., 2013). In the MK-801 rodent model of first-episode psychosis, we have previously reported a facilitated late-onset LTP restricted to glutamatergic synapses between CA1 and subicular bursting pyramidal cells (Bartsch et al., 2015). This form of subicular LTP is expressed presynaptically. Here, we show that single systemic MK-801 application also facilitates the induction of a noncanonical, but postsynaptic LTP at glutamatergic CA1-subiculum synapses to regular-firing neurons in the ventral hippocampus: buffering postsynaptic $\mathrm{Ca}^{2+}$ signals prevented LTP induction in regular-firing subicular neurons and, in contrast to LTP at CA1 inputs to bursting subicular neurons, LTP in regular-firing neurons was not accompanied by changes in the PPI. Apparently, cell type-specific forms of synaptic plasticity at CA1 inputs to subicular neurons appear in the MK-801 rodent model of first-episode psychosis as well. Two subsets of CA1 terminals with different susceptibility to express a presynaptic form of LTP seem to exist and determine the target-specificity of CA1 inputs to subicular neurons (Fidzinski et al., 2008; Wozny et al., 2008a; Wójtowicz et al., 2010). Cell type-specific forms of subicular LTP might be of important functional relevance. Theoretical and evidence-based theories imply that postsynaptic forms of LTP lead to an unconditional gain of synaptic transmission (Selig et al., 1999) whereas presynaptic forms of LTP redistribute existing synaptic efficacy and thereby alter the dynamics of synaptic transmission (Markram and Tsodyks, 1996). The specific role of both types of subicular neurons during behavior has yet to be determined.

\section{Dopamine-Dependent Long-Term Potentiation at Hippocampal Output Synapses in a Rodent Model of First-Episode Psychosis}

Several lines of evidence support a D1/D5R-dependent induction mechanism of the facilitated LTP in subicular 
regular-firing neurons in the MK-801 rodent model of firstepisode psychosis. First, blocking D1/D5R with a specific antagonist prevented LTP induction, second, activating D1/D5R with a specific agonist mimicked LTP in MK-801-treated rats and, finally, occluded HFS-induced LTP. This mechanism is consistent with the D1/D5R-dependent facilitated LTP in bursting subicular neurons in MK-801-treated rats (Bartsch et al., 2015) yet differs from it in terms of expression site. In MK-801-treated rats, LTP in regular-firing neurons is dependent on postsynaptic $\mathrm{Ca}^{2+}$ signaling while LTP in bursting neurons is not. Previous studies have already shown that D1/D5R activation facilitates either pre- or postsynaptic LTP depending on the subicular cell type (Roggenhofer et al., 2010, 2013). However, facilitated subicular LTP in the MK-801 rodent model of first-episode psychosis is noncanonical in that it is NMDAR-independent and exhibits a differential time course (late-onset) compared with canonical subicular LTP (initial strong post-tetanic potentiation decaying to a stable plateau).

Several origins of hippocampus-projecting dopaminergic fibers and a differential innervation along the hippocampal longitudinal axis have been described. Especially dopaminergic fibers arising from the ventral tegmental area and the substantia nigra pars compacta have been suggested to target the ventral hippocampal sector (reviewed in Edelmann and Lessmann, 2018). Notably, systemic NMDAR application can boost dopamine release in many brain regions (Deutch et al., 1987; Whitton et al., 1992; Breier et al., 1998). Relating to our findings, electrical HFS of the subiculum or regional NMDA application in the subiculum can initiate dopamine release from ventral tegmental area terminals projecting to the hippocampus (Blaha et al., 1997; Taepavarapruk et al., 2000; Floresco et al., 2001, 2003) that most prominently innervate CA1 and the subiculum (Verney et al., 1985). Hence, an increased hippocampal output after systemic MK-801 application represented by the aberrant noncanonical LTP in ventral subicular regular-firing neurons in this study may initiate a positive feedback in the hippocampusventral tegmental area loop and in turn, trigger an overdrive of the dopaminergic system. This scenario would be well in agreement with models proposing a hyperactive ventral hippocampus driving mesolimbic dopaminergic hyperfunction and resulting in aberrant dopaminergic signaling (Lodge and Grace, 2007). The distinct susceptibility of ventral subicular pyramidal cells to endogenously released dopamine could result from a region-specific distribution of dopamine receptor subtypes. However, D1R and D5R are expressed in pyramidal cells of the hippocampus proper and prominently in the ventral subiculum in rats (Fremeau et al., 1991). Immunohistochemical staining suggests that D5R mostly reside on cell bodies than on dendrites (Ciliax et al., 2000; Khan et al., 2000). Thus, the number of activated D1/D5R may determine differences in dopamine-dependent LTP facilitation in CA1 and the subiculum.

Considering the postsynaptic expression of LTP reported in this study, the most plausible mechanistic flow, therefore, seems to be the following: after systemic NMDAR antagonism, brief HFS can activate D1/D5R presumably via endogenous dopamine release. Activation of $\mathrm{D} 1 / \mathrm{D} 5 \mathrm{R}$, in turn, elevates postsynaptic cAMP concentrations and initiates the cAMP-PKA cascade by a Gs-adenylate cyclase pathway in subicular regular-firing neurons (Missale et al., 1998). This increases postsynaptic $\mathrm{Ca}^{2+}$ signaling via NMDAR-independent mechanisms (Cepeda et al., 1993, 1998; Surmeier et al., 1995; Hernández-López et al., 1997) which could modulate the membrane potential, favor EPSP summation and thereby lower the induction threshold for LTP resulting in a facilitated LTP.

\section{Possible Functional Impact of the Aberrant Noncanonical LTP in Ventral Subicular Regular-Firing Neurons}

A functional segregation along the longitudinal axis of the hippocampus has been suggested (Moser and Moser, 1998). The dorsal (septal) sector of the hippocampus, corresponding to the human posterior hippocampus, is mostly involved in spatial memory function while the ventral (temporal) pole of the hippocampus, corresponding to the human anterior hippocampus, modulates emotional, motivational and affective processes (reviewed in Fanselow and Dong, 2010; reviewed in Strange et al., 2014). Schizophrenia is associated with anterior hippocampal pathology (Titone et al., 2004; Öngür et al., 2006; Small et al., 2011; Lieberman et al., 2018). The ability to express LTP also varies along the septotemporal axis of the hippocampus: ventral CA1 expresses lower LTP compared with dorsal CA1 but this can change under pathophysiological conditions (Maggio and Segal, 2007a,b, 2011). Bearing in mind the pivotal role of the subiculum as information gatekeeper between the hippocampus and other brain regions, this aberrant LTP in ventral subicular regularfiring neurons is expected to interfere with physiological hippocampal output processing. Thereby, our results add to the notion from previous rodent studies suggesting that subregion-specific reduced synaptic plasticity or aberrant hyperplasticity contributes to hippocampal dysfunction in firstepisode psychosis (Tamminga et al., 2012a; Bartsch et al., 2019). Moreover, our observation of a cell type-specific facilitation of subicular LTP after systemic NMDAR antagonism can be considered as a form of metaplasticity. Metaplasticity is defined as a lasting modification in the neuronal state following activation which can hence regulate the duration, magnitude or direction of future synaptic plasticity (Abraham and Bear, 1996; Hulme et al., 2013). Related to first-episode psychosis, this metaplasticity might be maladaptive and could subsequently lead to hyperplasticity in key brain circuits associated with psychosis and schizophrenia (hippocampus-ventral tegmental area; hippocampus-medial prefrontal cortex) resulting in network dysregulation. Such network dysregulation is expected to contribute to the pathophysiology and perpetuation of acute psychotic symptoms and schizophrenia.

\section{DATA AVAILABILITY STATEMENT}

The datasets generated and analyzed during the current study are available from the corresponding author on reasonable request. 


\section{ETHICS STATEMENT}

The animal study was reviewed and approved by Landesamt für Gesundheit und Soziales Berlin (LAGeSo Berlin, Germany).

\section{AUTHOR CONTRIBUTIONS}

JCB and JB were responsible for conception of the study, design of the experiments and interpretation of the data and approved the final version and therefore agree to be accountable for all aspects of the work. JCB acquired and analyzed the data and wrote the manuscript with inputs from JB.

\section{REFERENCES}

Abraham, W. C., and Bear, M. F. (1996). Metaplasticity: the plasticity of synaptic plasticity. Trends Neurosci. 19, 126-130. doi: 10.1016/s0166-2236(96)80018-x

Aggleton, J. P., and Christiansen, K. (2015). The subiculum: the heart of the extended hippocampal system. Prog. Brain Res. 219, 65-82. doi: 10.1016/bs.pbr. 2015.03.003

Aoto, J., Martinelli, D. C., Malenka, R. C., Tabuchi, K., and Südhof, T. C. (2013). Presynaptic neurexin-3 alternative splicing trans-synaptically controls postsynaptic AMPA receptor trafficking. Cell 154, 75-88. doi: 10.1016/j.cell. 2013.05.060

Averbeck, B. B., and Chafee, M. V. (2016). Using model systems to understand errant plasticity mechanisms in psychiatric disorders. Nat. Neurosci. 19, 1418-1425. doi: 10.1038/nn.4413

Bannerman, D. M., Rawlins, J. N. P., McHugh, S. B., Deacon, R. M. J., Yee, B. K., Bast, T., et al. (2004). Regional dissociations within the hippocampus-memory and anxiety. Neurosci. Biobehav. Rev. 28, 273-283. doi: 10.1016/j.neubiorev. 2004.03.004

Bartsch, J. C., Fidzinski, P., Huck, J. H., Hörtnagl, H., Kovács, R., Liotta, A., et al. (2015). Enhanced dopamine-dependent hippocampal plasticity after single MK-801 application. Neuropsychopharmacology 40, 987-995. doi: 10.1038/npp. 2014.276

Bartsch, J. C., Schott, B. H., and Behr, J. (2019). Hippocampal dysfunction in schizophrenia and aberrant hippocampal synaptic plasticity in rodent model psychosis: a selective review. Pharmacopsychiatry doi: 10.1055/a-0960-9846 [Epub ahead of print].

Behr, J., Empson, R. M., Schmitz, D., Gloveli, T., and Heinemann, U. (1996). Electrophysiological properties of rat subicular neurons in vitro. Neurosci. Lett. 220, 41-44. doi: 10.1016/s0304-3940(96)13242-0

Berry, M. S., and Pentreath, V. W. (1976). Criteria for distinguishing between monosynaptic and polysynaptic transmission. Brain Res. 105, 1-20. doi: 10.1016/0006-8993(76)90919-7

Blaha, C. D., Yang, C. R., Floresco, S. B., Barr, A. M., and Phillips, A. G. (1997). Stimulation of the ventral subiculum of the hippocampus evokes glutamate receptor-mediated changes in dopamine efflux in the rat nucleus accumbense. Eur. J. Neurosci. 9, 902-911. doi: 10.1111/j.1460-9568.1997. tb01441.x

Bliss, T. V., and Lomo, T. (1973). Long-lasting potentiation of synaptic transmission in the dentate area of the anaesthetized rabbit following stimulation of the perforant path. J. Physiol. 232, 331-356. doi: 10.1113/jphysiol.1973.sp010273

Bogerts, B. (1997). The temporolimbic system theory of positive schizophrenic symptoms. Schizophr. Bull. 23, 423-435. doi: 10.1093/schbul/23.3.423

Breier, A., Adler, C. M., Weisenfeld, N., Su, T. P., Elman, I., Picken, L., et al. (1998). Effects of NMDA antagonism on striatal dopamine release in healthy subjects: application of a novel PET approach. Synapse 29, 142-147. doi: 10.1002/(sici)1098-2396(199806)29:2<142::aid-syn5>3.0.co;2-7

Buck, N., Cali, S., and Behr, J. (2006). Enhancement of long-term potentiation at CA1-subiculum synapses in MK-801-treated rats. Neurosci. Lett. 392, 5-9. doi: 10.1016/j.neulet.2005.08.054

\section{FUNDING}

This work was supported by the German Research Foundation (DFG) grants to JB (BE 2011/6-1), and JCB (medical scholar of the GRK 1123).

\section{ACKNOWLEDGMENTS}

We thank Pawel Fidzinski and Christian Wozny for helpful discussion, and Olaf Maassen for excellent technical assistance. We acknowledge support from the German Research Foundation (DFG) and the Open Access Publication Fund of Charité-Universitätsmedizin Berlin.

Cepeda, C., Buchwald, N. A., and Levine, M. S. (1993). Neuromodulatory actions of dopamine in the neostriatum are dependent upon the excitatory amino acid receptor subtypes activated. Proc. Natl. Acad. Sci. U S A 90, 9576-9580. doi: 10.1073/pnas.90.20.9576

Cepeda, C., Colwell, C. S., Itri, J. N., Chandler, S. H., and Levine, M. S. (1998). Dopaminergic modulation of NMDA-induced whole cell currents in neostriatal neurons in slices: contribution of calcium conductances. J. Neurophysiol. 79, 82-94. doi: 10.1152/jn.1998.79.1.82

Ciliax, B. J., Nash, N., Heilman, C., Sunahara, R., Hartney, A., Tiberi, M., et al. (2000). Dopamine D5 receptor immunolocalization in rat and monkey brain. Synapse 37, 125-145. doi: 10.1002/1098-2396(200008)37:2<125::aid-syn7>3.0. co;2-7

Deutch, A. Y., Tam, S. Y., Freeman, A. S., Bowers, M. B., and Roth, R. H. (1987). Mesolimbic and mesocortical dopamine activation induced by phencyclidine: contrasting pattern to striatal response. Eur. J. Pharmacol. 134, 257-264. doi: 10.1016/0014-2999(87)90356-6

Edelmann, E., and Lessmann, V. (2018). Dopaminergic innervation and modulation of hippocampal networks. Cell Tissue Res. 373, 711-727. doi: 10.1007/s00441-018-2800-7

Fanselow, M. S. (2000). Contextual fear, gestalt memories, and the hippocampus. Behav. Brain Res. 110, 73-81. doi: 10.1016/s0166-4328(99)00186-2

Fanselow, M. S., and Dong, H. W. (2010). Are the dorsal and ventral hippocampus functionally distinct structures? Neuron 65, 7-19. doi: 10.1016/j.neuron.2009. 11.031

Fidzinski, P., Shor, O., and Behr, J. (2008). Target-cell-specific bidirectional synaptic plasticity at hippocampal output synapses. Eur. J. Neurosci. 27, 1111-1118. doi: 10.1111/j.1460-9568.2008.06089.x

Floresco, S. B., Todd, C. L., and Grace, A. A. (2001). Glutamatergic afferents from the hippocampus to the nucleus accumbens regulate activity of ventral tegmental area dopamine neurons. J. Neurosci. 21, 4915-4922. doi: 10.1523/JNEUROSCI.21-13-04915.2001

Floresco, S. B., West, A. R., Ash, B., Moorel, H., and Grace, A. A. (2003). Afferent modulation of dopamine neuron firing differentially regulates tonic and phasic dopamine transmission. Nat. Neurosci. 6, 968-973. doi: 10.1038/nn1103

Fremeau, R. T. Jr., Duncan, G. E., Fornaretto, M. G., Dearry, A., Gingrich, J. A., Breese, G. R., et al. (1991). Localization of D1 dopamine receptor mRNA in brain supports a role in cognitive, affective and neuroendocrine aspects of dopaminergic neurotransmission. Proc. Natl. Acad. Sci. U S A 88, 3772-3776. doi: $10.1073 /$ pnas.88.9.3772

Hájos, N., Ellender, T. J., Zemankovics, R., Mann, E. O., Exley, R., Cragg, S. J., et al. (2009). Maintaining network activity in submerged hippocampal slices: importance of oxygen supply. Eur. J. Neurosci. 29, 319-327. doi: 10.1111/j.14609568.2008.06577.x

Hall, J., Trent, S., Thomas, K. L., O’Donovan, M. C., and Owen, M. J. (2015) Genetic risk for schizophrenia: convergence on synaptic pathways involved in plasticity. Biol. Psychiatry 77, 52-58. doi: 10.1016/j.biopsych.2014.07.011

Harris, E., and Stewart, M. (2001). Intrinsic connectivity of the rat subiculum: II. Properties of synchronous spontaneous activity and a demonstration of multiple generator regions. J. Comp. Neurol. 435, 506-518. doi: 10.1002/ cne. 1047 
Heckers, S., Rauch, S., Goff, D., Savage, C., Schacter, D., Fischman, A., et al. (1998). Impaired recruitment of the hippocampus during conscious recollection in schizophrenia. Nat. Neurosci. 1, 318-323. doi: 10.1038/1137

Hernández-López, S., Bargas, J., Surmeier, D. J., Reyes, A., and Galarraga, E. (1997). Receptor activation enhances evoked discharge in neostriatal medium spiny neurons by modulating an L-type $\mathrm{Ca}^{2+}$ conductance. J. Neurosci. 17, 3334-3342. doi: 10.1523/JNEUROSCI.17-09-03334.1997

Hulme, S. R., Jones, O. D., and Abraham, W. C. (2013). Emerging roles of metaplasticity in behaviour and disease. Trends Neurosci. 36, 353-362. doi: $10.1016 /$ j.tins.2013.03.007

Jarrard, L. E. (1995). What does the hippocampus really do? Behav. Brain Res. 71, 1-10. doi: 10.1016/0166-4328(95)00034-8

Khan, Z. U., Gutiérrez, A., Martín, R., Peñafiel, A., Rivera, A., and de la Calle, A. (2000). Dopamine D5 receptors of rat and human brain. Neuroscience 100, 689-699. doi: 10.1016/s0306-4522(00)00274-8

Kim, Y., and Spruston, N. (2012). Target-specific output patterns are predicted by the distribution of regular-spiking and bursting pyramidal neurons in the subiculum. Hippocampus 22, 693-706. doi: 10.1002/hipo.20931

Köhler, C. (1985). Intrinsic projections of the retrohippocampal region in the rat brain. I. The subicular complex. J. Comp. Neurol. 236, 504-522. doi: 10.1002/cne.902360407

Lapointe, V., Morin, F., Ratté, S., Croce, A., Conquet, F., and Lacaille, J. C. (2004). Synapse-specific mGluR1-dependent long-term potentiation in interneurones regulates mouse hippocampal inhibition. J. Physiol. 555, 125-135. doi: 10.1113/jphysiol.2003.053603

Lieberman, J. A., Girgis, R. R., Brucato, G., Moore, H., Provenzano, F., Kegeles, L., et al. (2018). Hippocampal dysfunction in the pathophysiology of schizophrenia: a selective review and hypothesis for early detection and intervention. Mol. Psychiatry 23, 1764-1772. doi: 10.1038/mp.2017.249

Lodge, D. J., and Grace, A. A. (2007). Aberrant hippocampal activity underlies the dopamine dysregulation in an animal model of schizophrenia. J. Neurosci. 27, 11424-11430. doi: 10.1523/JNEUROSCI.2847-07.2007

Luby, E. D., Cohen, B. D., Rosenbaum, G., Gottlieb, J. S., and Kelley, R. (1959). Study of a new schizophrenomimetic drug-sernyl. Arch. Neurol. Psychiatry 81, 363-369. doi: 10.1001/archneurpsyc.1959.02340150095011

Maggio, N., and Segal, M. (2007a). Striking variations in corticosteroid modulation of long-term potentiation along the septotemporal axis of the hippocampus. J. Neurosci. 27, 5757-5765. doi: 10.1523/JNEUROSCI.0155-07.2007

Maggio, N., and Segal, M. (2007b). Unique regulation of long term potentiation in the rat ventral hippocampus. Hippocampus 17, 10-25. doi: 10.1002/hipo. 20237

Maggio, N., and Segal, M. (2011). Persistent changes in ability to express long-term potentiation/depression in the rat hippocampus after juvenile/adult stress. Biol. Psychiatry 69, 748-753. doi: 10.1016/j.biopsych.2010.11.026

Maren, S. (1999). Neurotoxic or electrolytic lesions of the ventral subiculum produce deficits in the acquisition and expression of Pavlovian fear conditioning in rats. Behav. Neurosci. 113, 283-290. doi: 10.1037/0735-7044. 113.2.283

Markram, H., and Tsodyks, M. (1996). Redistribution of synaptic efficacy between neocortical pyramidal neurons. Nature 382, 807-810. doi: 10.1038/382807a0

Mattia, D., Kawasaki, H., and Avoli, M. (1997). In vitro electrophysiology of rat subicular bursting neurons. Hippocampus 7, 48-57. doi: 10.1002/(sici)10981063(1997)7:1<48::aid-hipo5>3.0.co;2-3

McGlashan, T. H. (2006). Schizophrenia in translation: is active psychosis neurotoxic? Schizophr. Bull. 32, 609-613. doi: 10.1093/schbul/sbl032

Miles, R., and Wong, R. K. (1987). Inhibitory control of local excitatory circuits in the guinea-pig hippocampus. J. Physiol. 388, 611-629. doi: 10.1113/jphysiol. 1987.sp016634

Missale, C., Nash, S. R., Robinson, S. W., Jaber, M., and Caron, M. G. (1998). Dopamine receptors: from structure to function. Physiol. Rev. 78, 189-225. doi: 10.1152/physrev.1998.78.1.189

Morris, R. G. M. (2013). NMDA receptors and memory encoding. Neuropharmacology 74, 32-40. doi: 10.1016/j.neuropharm.2013.04.014

Moser, M. B., and Moser, E. I. (1998). Functional differentiation in the hippocampus. Hippocampus 8, 608-619. doi: 10.1002/(sici)10981063(1998)8:6<608::aid-hipo3>3.0.co;2-7

Neill, J. C., Barnes, S., Cook, S., Grayson, B., Idris, N. F., McLean, S. L., et al. (2010). Animal models of cognitive dysfunction and negative symptoms of schizophrenia: focus on NMDA receptor antagonism. Pharmacol. Ther. 128, 419-432. doi: 10.1016/j.pharmthera.2010.07.004

Nicholls, J. G., and Purves, D. (1970). Monosynaptic chemical and electrical connexions between sensory and motor cells in the central nervous system of the leech. J. Physiol. 209, 647-667. doi: 10.1113/jphysiol.1970.sp009184

Nicoll, R. A., and Malenka, R. C. (1999). Expression mechanisms underlying NMDA receptor-dependent long- term potentiation. Ann. N Y Acad. Sci. 868, 515-525. doi: 10.1111/j.1749-6632.1999.tb11320.x

O'Leary, D. M., and O'Connor, J. J. (1999). Potentiation of synaptic transmission by (S)-3,5-dihydroxy phenylglycine in the rat dentate gyrus in vitro: a role for voltage dependant calcium channels and protein kinase C. Prog. Neuropsychopharmacol. Biol. Psychiatry 23, 133-147. doi: 10.1016/s02785846(98)00095-5

O’Mara, S. M., Commins, S., and Anderson, M. (2000). Synaptic plasticity in the hippocampal area CA1-subiculum projection: implications for theories of memory. Hippocampus 10, 447-456. doi: 10.1002/10981063(2000)10:4<447::aid-hipo11>3.0.co;2-2

Öngür, D., Cullen, T. J., Wolf, D. H., Rohan, M., Barreira, P., Zalesak, M., et al. (2006). The neural basis of relational memory deficits in schizophrenia. Arch. Gen. Psychiatry 63, 356-365. doi: 10.1001/archpsyc.63.4.356

Pirnia, T., Woods, R. P., Hamilton, L. S., Lyden, H., Joshi, S. H., Asarnow, R. F., et al. (2015). Hippocampal dysfunction during declarative memory encoding in schizophrenia and effects of genetic liability. Schizophr. Res. 161, 357-366. doi: 10.1016/j.schres.2014.11.030

Ragland, J. D., Ranganath, C., Harms, M. P., Barch, D. M., Gold, J. M., Layher, E., et al. (2015). Functional and neuroanatomic specificity of episodic memory dysfunction in schizophrenia. JAMA Psychiatry 72, 909-916. doi: 10.1001/jamapsychiatry.2015.0276

Roggenhofer, E., Fidzinski, P., Bartsch, J., Kurz, F., Shor, O., and Behr, J. (2010). Activation of dopamine D1/D5 receptors facilitates the induction of presynaptic long-term potentiation at hippocampal output synapses. Eur. J. Neurosci. 32, 598-605. doi: 10.1111/j.1460-9568.2010.07312.x

Roggenhofer, E., Fidzinski, P., Shor, O., and Behr, J. (2013). Reduced threshold for induction of LTP by activation of dopamine D1/D5 receptors at hippocampal CA1-subiculum synapses. PLoS One 8:e62520. doi: 10.1371/journal.pone. 0062520

Schneggenburger, R., Sakaba, T., and Neher, E. (2002). Vesicle pools and short-term synaptic depression: lessons from a large synapse. Trends Neurosci. 25, 206-212. doi: 10.1016/s0166-2236(02)02139-2

Schott, B. H., Voss, M., Wagner, B., Wüstenberg, T., Düzel, E., and Behr, J. (2015). Fronto-limbic novelty processing in acute psychosis: disrupted relationship with memory performance and potential implications for delusions. Front. Behav. Neurosci. 9:144. doi: 10.3389/fnbeh.2015.00144

Segal, M., Richter-Levin, G., and Maggio, N. (2010). Stress-induced dynamic routing of hippocampal connectivity: a hypothesis. Hippocampus 20, 1332-1338. doi: 10.1002/hipo.20751

Selig, D. K., Nicoll, R. A., and Malenka, R. C. (1999). Hippocampal long-term potentiation preserves the fidelity of postsynaptic responses to presynaptic bursts. J. Neurosci. 19, 1236-1246. doi: 10.1523/JNEUROSCI.19-04-01236.1999

Sharp, P. E. (1999). Complimentary roles for hippocampal versus subicular/entorhinal place cells in coding place, context, and events. Hippocampus 9, 432-443. doi: 10.1002/(sici)1098-1063(1999)9:4<432::aidhipo9>3.0.co;2-p

Small, S. A., Schobel, S. A., Buxton, R. B., Witter, M. P., and Barnes, C. A. (2011). A pathophysiological framework of hippocampal dysfunction in ageing and disease. Nat. Rev. Neurosci. 12, 585-601. doi: 10.1038/nrn3085

Staff, N. P., Jung, H. Y., Thiagarajan, T., Yao, M., and Spruston, N. (2000). Resting and active properties of pyramidal neurons in subiculum and CA1 of rat hippocampus. J. Neurophysiol. 84, 2398-2408. doi: 10.1152/jn.2000.84.5.2398

Stewart, M. (1997). Antidromic and orthodromic responses by subicular neurons in rat brain slices. Brain Res. 769, 71-85. doi: 10.1016/s0006-8993(97) 00690-2

Stewart, M., and Wong, R. K. S. (1993). Intrinsic properties and evoked responses of guinea pig subicular neurons in vitro. J. Neurophysiol. 70, 232-245. doi: 10.1152/jn.1993.70.1.232

Strange, B. A., Witter, M. P., Lein, E. S., and Moser, E. I. (2014). Functional organization of the hippocampal longitudinal axis. Nat. Rev. Neurosci. 15, 655-669. doi: 10.1038/nrn3785 
Surmeier, D. J., Bargas, J., Hemmings, H. C. Jr., Nairn, A. C., and Greengard, P. (1995). Modulation of calcium currents by a D1 dopaminergic protein kinase/phosphatase cascade in rat neostriatal neurons. Neuron 14, 385-397. doi: 10.1016/0896-6273(95)90294-5

Taepavarapruk, P., Floresco, S. B., and Phillips, A. G. (2000). Hyperlocomotion and increased dopamine efflux in the rat nucleus accumbens evoked by electrical stimulation of the ventral subiculum: role of ionotropic glutamate and dopamine D1 receptors. Psychopharmacology 151, 242-251. doi: $10.1007 / \mathrm{s} 002130000376$

Tamminga, C. A., Southcott, S., Sacco, C., Wagner, A. D., and Ghose, S. (2012a). Glutamate dysfunction in hippocampus: relevance of dentate gyrus and CA3 signaling. Schizophr. Bull. 38, 927-935. doi: 10.1093/schbul/sbs062

Tamminga, C. A., Thomas, B. P., Chin, R., Mihalakos, P., Youens, K., Wagner, A. D., et al. (2012b). Hippocampal novelty activations in schizophrenia: disease and medication effects. Schizophr. Res. 138, 157-163. doi: 10.1016/j.schres.2012.03.019

Taube, J. S. (1993). Electrophysiological properties of neurons in the rat subiculum in vitro. Exp. Brain Res. 96, 304-318. doi: 10.1007/bf00227110

Titone, D., Ditman, T., Holzman, P. S., Eichenbaum, H., and Levy, D. L. (2004). Transitive inference in schizophrenia: impairments in relational memory organization. Schizophr. Res. 68, 235-247. doi: 10.1016/s0920-9964(03)00152-X

Verney, C., Baulac, M., Berger, B., Alvarez, C., Vigny, A., and Helle, K. B. (1985). Morphological evidence for a dopaminergic terminal field in the hippocampal formation of young and adult rat. Neuroscience 14, 1039-1052. doi: 10.1016/0306-4522(85)90275-1

Volianskis, A., France, G., Jensen, M. S., Bortolotto, Z. A., Jane, D. E., and Collingridge, G. L. (2015). Long-term potentiation and the role of N-methyld-aspartate receptors. Brain Res. 1621, 5-16. doi: 10.1016/j.brainres.2015. 01.016

Wellmer, J., Su, H., Beck, H., and Yaari, Y. (2002). Long-lasting modification of intrinsic discharge properties in subicular neurons following status epilepticus. Eur. J. Neurosci. 16, 259-266. doi: 10.1046/j.1460-9568.2002.02086.x

Whitton, P. S., Biggs, C. S., Pearce, B. R., and Fowler, L. J. (1992). Regional effects of MK-801 on dopamine and its metabolites studied by in vivo microdialysis. Neurosci. Lett. 142, 5-8. doi: 10.1016/0304-3940(92)90607-9
Wigström, H., and Gustafsson, B. (1983). Facilitated induction of hippocampal long-lasting potentiation during blockade of inhibition. Nature 301, 603-604. doi: 10.1038/301603a0

Wöhrl, R., Eisenach, S., Manahan-Vaughan, D., Heinemann, U., and von Haebler, D. (2007). Acute and long-term effects of MK-801 on direct cortical input evoked homosynaptic and heterosynaptic plasticity in the CA1 region of the female rat. Eur. J. Neurosci. 26, 2873-2883. doi: 10.1111/j.1460-9568.2007. 05899.x

Wójtowicz, A. M., Fidzinski, P., Heinemann, U., and Behr, J. (2010). Betaadrenergic receptor activation induces long-lasting potentiation in burstspiking but not regular-spiking cells at CA1-subiculum synapses. Neuroscience 171, 367-372. doi: 10.1016/j.neuroscience.2010.09.028

Wozny, C., Maier, N., Fidzinski, P., Breustedt, J., Behr, J., and Schmitz, D. (2008a). Differential cAMP signaling at hippocampal output synapses. J. Neurosci. 28 , 14358-14362. doi: 10.1523/JNEUROSCI.4973-08.2008

Wozny, C., Maier, N., Schmitz, D., and Behr, J. (2008b). Two different forms of long-term potentiation at CA1-subiculum synapses. J. Physiol. 586, 2725-2734. doi: 10.1113/jphysiol.2007.149203

Zierhut, K., Bogerts, B., Schott, B., Fenker, D., Walter, M., Albrecht, D., et al. (2010). The role of hippocampus dysfunction in deficient memory encoding and positive symptoms in schizophrenia. Psychiatry Res. Neuroimaging 183, 187-194. doi: 10.1016/j.pscychresns.2010.03.007

Zucker, R. S., and Regehr, W. G. (2002). Short-term synaptic plasticity. Annu. Rev. Physiol. 64, 355-405. doi: 10.1146/annurev.physiol.64.092501.114547

Conflict of Interest: The authors declare that the research was conducted in the absence of any commercial or financial relationships that could be construed as a potential conflict of interest.

Copyright (c) 2020 Bartsch and Behr. This is an open-access article distributed under the terms of the Creative Commons Attribution License (CC BY). The use, distribution or reproduction in other forums is permitted, provided the original author(s) and the copyright owner(s) are credited and that the original publication in this journal is cited, in accordance with accepted academic practice. No use, distribution or reproduction is permitted which does not comply with these terms. 